\title{
Pattern separation by neuronal turnover in a feed-forward network
}

\author{
Anthony J DeCostanzo*, Tomoki Fukai \\ From Twenty Second Annual Computational Neuroscience Meeting: CNS*2013 \\ Paris, France. 13-18 July 2013
}

Numerous studies have revealed a role for the hippocampal dentate gyrus in behavioral discrimination between similar contexts or objects, referred to as pattern separation. Recently many behavioral studies have demonstrated a role for dentate neurogenesis in such pattern separation. While several computational studies have modeled the effect of neuronal turnover on learning in simple [1-3] and more detailed networks [4], the computational advantage of neurogenesis for pattern separation has remained obscure. Here we present a simple, feed-forward network, with a biologically plausible learning rule for implementing neuronal recycling that reveals the pattern separation properties of neurogenesis. Our model consists of a three-layer network including entorhinal cortical inputs (EC), dentate gyrus (DG) as the hidden layer, and a single $\mathrm{CA} 3$ readout unit. The weights between EC and DG are fixed random, while those from DG to CA3 are trained with a perceptron learning rule. A "context" consists of a set of patterns presented to EC with their respective target readouts at CA3. Pereceptron training results in a weight vector with approximately normally distributed weights. Neurogenesis is implemented by replacing units with weak weights to the CA3 readout, thus a new hidden unit with random weights replaces the prior unit. Thereupon another round of perceptron learning is implemented. This simple rule results in a markedly reduced generalization error at the CA3 readout that continues to decline with each subsequent round of neurogenesis. Intuitively, this neurogenesis improves linear separability in the DG space allowing the CA3 readout to draw a decision hyperplane with a greater margin between the classes. This form of neuronal turnover may represent a biologically plausible replacement for error backpropagation.

\footnotetext{
* Correspondence: anthony.decostanzo@riken.jp

C Biomed Central
}

Brain Science Institute, RIKEN, Wakoshi, Saitama, Japan

\section{Acknowledgements}

This work was partly supported by Grants-in-Aid for Scientific Research on Innovative Areas (KAKENHI, no. 22115013) and CREST, Japan Science and Technology.

Published: 8 July 2013

\section{References}

1. Cecchi GA, Petreanu LT, Alvarez-Buylla A, Magnasco MO: Unsupervised learning and adaptation in a model of adult neurogenesis. $J$ Comput Neurosci 2001, 11(2):175-82.

2. Chambers RA, Potenza MN, Hoffman RE, Miranker W: Simulated apoptosis/ neurogenesis regulates learning and memory capabilities of adaptive neural networks. Neuropsychopharmacology 2004, 29(4):747-58.

3. Wiskott L, Rasch MJ, Kempermann G: A functional hypothesis for adult hippocampal neurogenesis: avoidance of catastrophic interference in the dentate gyrus. Hippocampus 2006, 16(3):329-43.

4. Aimone JB, Wiles J, Gage FH: Computational influence of adult neurogenesis on memory encoding. Neuron 2009, 61(2):187-202, doi: 10.1016/j.neuron.2008.11.026.

doi:10.1186/1471-2202-14-S1-P135

Cite this article as: DeCostanzo and Fukai: Pattern separation by neuronal turnover in a feed-forward network. BMC Neuroscience 201314 (Suppl 1):P135.
Submit your next manuscript to BioMed Central and take full advantage of:

- Convenient online submission

- Thorough peer review

- No space constraints or color figure charges

- Immediate publication on acceptance

- Inclusion in PubMed, CAS, Scopus and Google Scholar

- Research which is freely available for redistribution
() Biomed Central 